\title{
Master Bank or Seed Stock Immediate Supplier
}

National Cancer Institute

\section{Source}

National Cancer Institute. Master Bank or Seed Stock Immediate Supplier. NCI

Thesaurus. Code C158310.

The name of the direct supplier of the master bank or seed stock of org anisms from which the biological challenge agent came. 